\title{
Interannual variability of the lake levels in northwest Russia based on satellite altimetry
}

\author{
SERGEY A. LEBEDEV ${ }^{1,2}$, YULIA I. TROITSKAYA ${ }^{3}$, GALINA V. RYBUSHKINA ${ }^{3}$ \\ \& MICHAEL N. DOBROVOLSKY ${ }^{1}$ \\ 1 Geophysical Center of the Russian Academy of Sciences, 3 Molodezhnaya Str., 119296, Moscow, Russia \\ lebedev@,wdcb.ru \\ 2 Space Research Institute of the Russian Academy of Sciences, 84/32 Profsoyuznaya Str, 117997, Moscow, Russia \\ 3 Institute of Applied Physics of the Russian Academy of Sciences, 46 Ul'yanov Str., 603950, Nizhny Novgorod, Russia
}

\begin{abstract}
Variability of the largest lakes levels in northwest Russia, a climatic change parameter, is characterized by alternating periods of rise and fall according to altimetric measurements of the TOPEX/Poseidon and Jason-1/2 satellites. Water level was calculated with the use of a regional adaptive retracking algorithm for the lakes Il'men, Ladoga, Onega and Peipus. Applications of this algorithm considerably increase the quantity of actual data records and significantly improve the accuracy of water level evaluation. According to the results, temporal variability of Lake Ilmen, Lake Ladoga and Lake Piepus levels is characterized by a wave with a period of 4-5 years, and that of Lake Onega level is characterized by a wave with a period of 15 years. During the period from 1993 to 2011 , lake level rose at a rate of $1.17 \pm 0.95 \mathrm{~cm} /$ year for Lake Il'men, $0.24 \pm 0.10 \mathrm{~cm} /$ year for Lake Ladoga, $1.39 \pm 0.18 \mathrm{~cm} /$ year for Lake Piepus and $0.18 \pm 0.09$ $\mathrm{cm} /$ year for Lake Onega.
\end{abstract}

Key words northwest Russian lakes; Lake Il'men; Lake Ladoga; Lake Onega; Lake Peipus; water lake level; remote sensing; satellite altimetry

\section{INTRODUCTION}

Remote sensing, particularly the use of radar altimeters, offers a global perspective for some hydrological parameters. Satellite radar altimetry, with its all-weather operation, can be used to derive lake, river and wetland levels. These remote sensing measurements can be applied to several programmes including the determination of regional-scale hydrological variability due to climate change in drainage basins.

One of the recent applications of satellite altimetry, which was originally designed for measurements of sea level, is associated with remote investigation of the water level of inland waters: lakes, rivers, reservoirs. The possibility of using altimetry data for determining hydrological characteristics of inland basins is being studied with the aim of determining the hydrological regime of large rivers in South America, Africa and Siberia (Campos et al. 2001, Birkett et al. 2002, Kouraev et al. 2004, Birkett and Beckley, 2010), as well as for assessing water level in the lower reaches of the Volga River (Lebedev and Kostianoy, 2005), Volga River reservoirs (Troitskaya et al. 2012a,b; 2013) and other inland basins (Berry et al. 2005). Numerous applications of satellite altimetry to monitoring of inland waters are reviewed in Calmant and Seyler (2006) and Cretaux et al. (2011).

Standard altimetry data processing developed for open ocean conditions cannot be used in the case of inland waters, where reflection from the land dramatically alters the altimeter waveforms and leads to significant errors in estimation of the water level. Appreciable scatter of satellite data can be explained by the shortcomings of direct extension of the algorithms of water level calculation developed for large water basins (seas and oceans) to medium area basins where the radar return is significantly contaminated by reflection from the land. This effect is very strong in the Volga reservoirs with a width of 10-15 km (except for the Rybinsk reservoir). Under these conditions very few telemetric impulses fit the validity criteria, which cause a severe loss of data. The problem of minimization of errors in the water level retrieval for inland waters from altimetry measurements can be resolved by retracking satellite altimetry data. Recently, special retracking algorithms have been developed for re-processing altimetry data in the coastal zone where reflection from land strongly affects echo shapes: threshold retracking, $\beta$-retracking (Davis 1997, Deng and Featherstone 2006), and three new retrackers to improve the accuracy of altimetry observations were proposed in (Guo et 


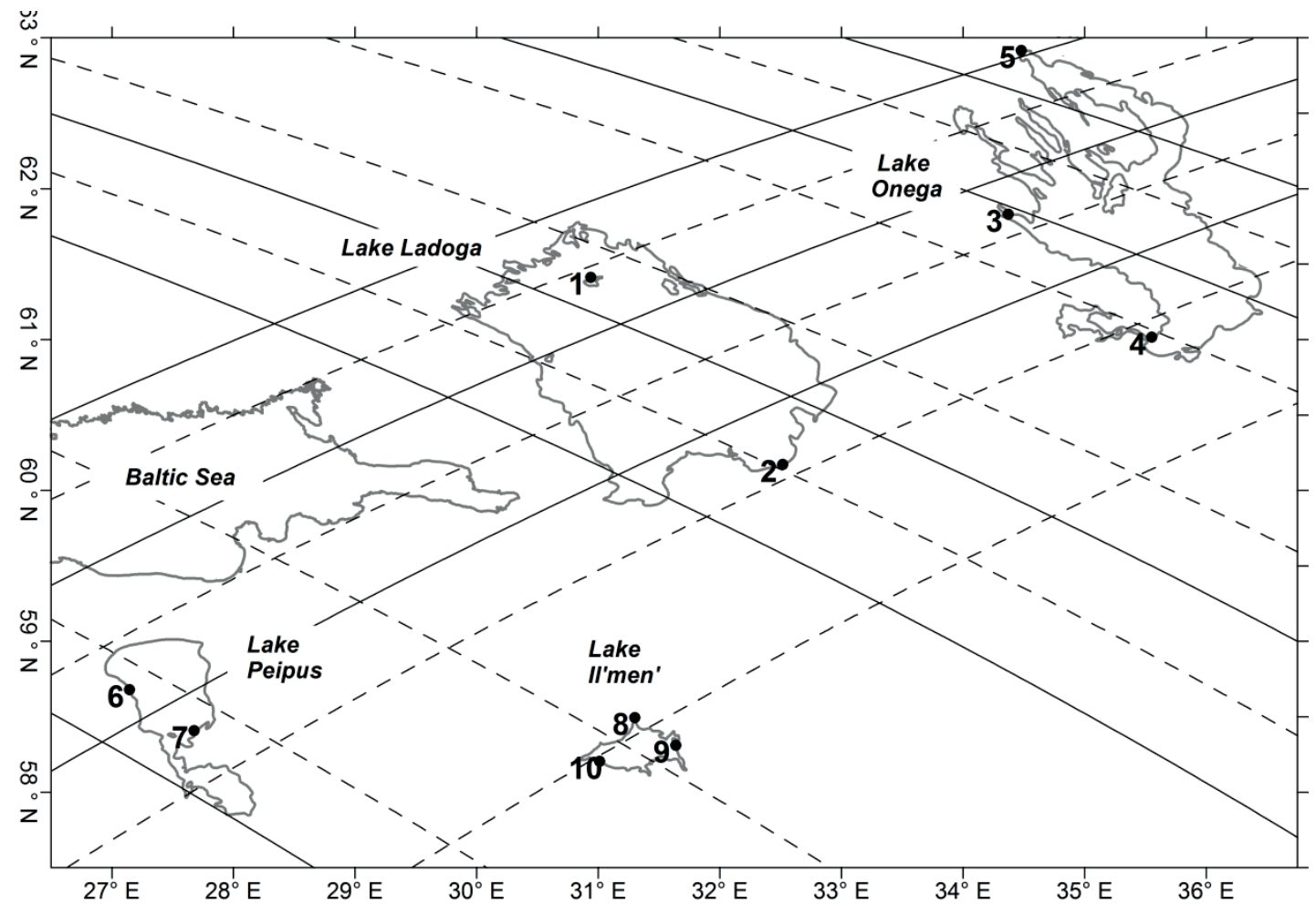

Fig. 1 Position of the T/P and J1/2 satellites groundtracks before (solid line) and after (dashed line) the manoeuver in the water area Lake Ladoga, Lake Onega, Lake Peipus and Lake Il'men'. Black cycles show water level gauges: (1) Balaam and (2) Siaskie Ryadki (Lake Ladoga); (3) Petrozavodsk, (4) Voznesenie and (5) Medvezhyegorsk (Lake Onega); (6) Mustvee and (7) Raskopel (Lake Peipus); (8) Volkhov-Novgorod, (9) Voytsy and (10) Korostyn (Lake Il'men).

al. 2009). The latest development in this field is the PISTACH (Prototype Innovant de Système de Traitement pour les Applications Côtières et l'Hydrologie) product (Mercier et al. 2010), in which retracking is based on the classification of typical forms of telemetric waveforms in the coastal zones and inland water bodies (see also references in Troitskaya et al. 2012a,b; 2013).

A new method of regional adaptive retracking based on constructing a theoretical model describing the formation of telemetric waveforms by reflection from the piecewise constant model surface corresponding to the geography of the region was proposed in (Troitskaya et al. 2012a,b), and an algorithm for assessing water level in inland water basins and in the coastal zone of the ocean with an error of about $10-15 \mathrm{~cm}$ was constructed. This algorithm was tested using the satellites TOPEX/Poseidon (T/P) and Jason-1/2 (J1/2) for the Gorky Reservoir which has complex topography, and where the standard Ocean-1 algorithm is not applicable. In Troitskaya et al. (2012b) a model of an average waveform reflected from a statistically inhomogeneous piecewise constant surface (topographic model) was used for theoretical calculation of the reflected power on the basis of the work of Brown (1977) and Barrick and Lipa (1985). The model allowed substantiation of data selection criteria for the Gorky Reservoir. The water level was calculated by means of regional adaptive retracking of the SGDR (sensory geophysical data record) database for the Gorky Reservoir, and it was shown that application of this algorithm greatly increases the number of included data and the accuracy of water level determination. General principles of the proposed algorithm for complicated areas (coastal zones, inland waters, and so on) based on calculations of the signal with allowance for inhomogeneity of a reflecting surface, may be used in different geographical regions.

In our work, this algorithm is used for reprocessing data for several passes of the T/P and J1/2 satellites over four lakes: Ladoga, Onega, Il'men and Peipus (Fig. 1), the physical geographic parameters of which are presented in Table 1. The coastal topography of the lakes differs 
Table 1 Physical geographic parameters of the northwest Russian lakes.

\begin{tabular}{lrrrr}
\hline Parameter & Lake Ladoga & Lake Onega & Lake Il'men & Lake Peipus \\
\hline Drainage basin $\left(\mathrm{km}^{2}\right)$ & 276000.0 & 66284.0 & 67200.0 & 47800.0 \\
Max. length $(\mathrm{km})$ & 219.0 & 245.0 & 40.0 & 152.0 \\
Max. width $(\mathrm{km})$ & 138.0 & 91.6 & 32.0 & 47.0 \\
Surface area $\left(\mathrm{km}^{2}\right)$ & 17800.0 & 9720.0 & 982.0 & 3555.0 \\
Average depth $(\mathrm{m})$ & 51.0 & 30.0 & 4.4 & 7.1 \\
Max. depth $(\mathrm{m})$ & 230.0 & 127.0 & 10.0 & 15.3 \\
Water volume $\left(\mathrm{km}^{3}\right)$ & 837.0 & 285.0 & 12.0 & 25.0 \\
Surface elevation $(\mathrm{m})$ & 5.0 & 33.0 & & 30.0 \\
Shore length $(\mathrm{km})$ & 1570.0 & & & 520.0 \\
Islands & 660 & 1,369 & & 29 \\
Islands area $\left(\mathrm{km}^{2}\right)$ & 535.0 & 30.0 & November-April & December-April \\
Freezing period & February-May & January-May & &
\end{tabular}

significantly. The shores of all the lakes are primarily low grasslands, forests and wetlands, but Lake Ladoga and Lake Onega have a large number of islands. They are located near to northern and northeastern shores, which are high and sometimes steep.

\section{ADAPTIVE RETRACKING OF SATELLITE ALTIMETRY DATA}

In the presence of additional peaks generated by reflection from land, a smooth coastal water surface and highly reflective coastal objects (buildings, slicks, etc.), the reflected waveforms are poorly approximated by Brown's formula (Brown 1977, Barrick and Lipa 1985), which leads to errors in determining the position of the leading edge and, hence, to wrong determination of satellite altitude and water level. In this case, other quantities, such as wind speed and significant wave height (SWH) are also determined incorrectly. The adaptive algorithm described in Troitskaya et al. 2012a,b) permits determining of the area of satellite pass over the water basin where reflection from the water determines the formation of the leading edge of the telemetric pulse and the influence of land is insignificant. The algorithm includes four consecutive steps:

- constructing a local piecewise model of a reflecting surface in the neighbourhood of the lake;

- solving a direct problem by calculating the reflected waveforms within the framework of the model;

- imposing restrictions and validity criteria for the algorithm based on waveform modelling;

- solving the inverse problem by retrieving a tracking point by the improved threshold algorithm.

The adaptive algorithm was tested for reprocessing of the T/P and J1/2 SGDR data in the Gorky and Rybinsk reservoirs of the Volga River and showed good accuracy for water level determination (Troitskaya et al. 2012a,b). Study of the possibility of applying this algorithm for northwest Russian lakes is of considerable interest, so as to make it more useful for inland water basins.

For modelling the formation of telemetric waveforms in accordance with the procedure of regional adaptive retracking (Troitskaya et al. 2012a), first we construct a piecewise constant model surface (Fig. 2) corresponding to the geography of the region. The model assumes three types of reflected surface: water, land and coastal slicks, which are long strips of smoothed water extending along coastlines. Such smoothed regions, 20-30 m wide, are regularly observed near the coastline (usually caused by high concentrations of surface-active substances) and are known to give rise to peaks in telemetric pulses (Tournadre et al. 2006). The coastal slicks that were revealed in the Gorky Reservoir water area by field studies can significantly influence the reflected waveforms (Troitskaya et al. 2012b).

In the case of inland water bodies, when the altimeter footprint is a combination of several different (in height and reflecting properties) parts, the total reflected power is a sum of contributions from all piecewise-constant areas (Troitskaya et al. 2012b): 

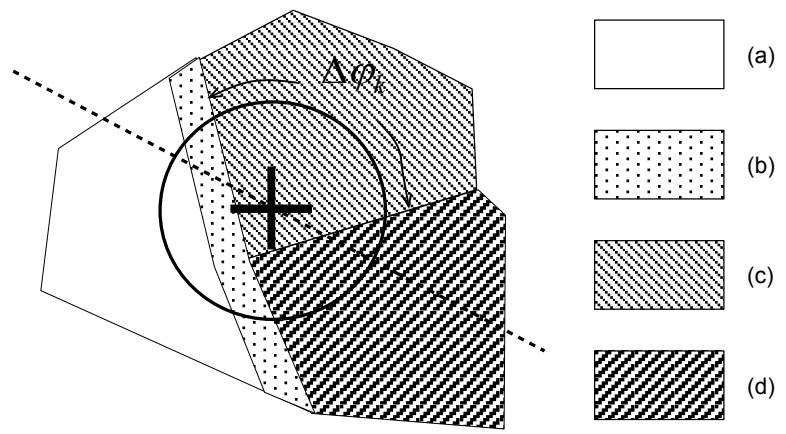

Fig. 2 Piecewise constant model of underlying surface (the plus sign denotes the position of nadir, the dotted line denotes the track of the satellite, the circle denotes the border of the illuminated area at a given time, (a) - the water, (b) - the slick and (c) and (d) - different types of land: swamp or forest).

$$
P(\tau)=P_{\text {water }}(\tau)+P_{\text {land }}(\tau)+P_{\text {coast }}(\tau)
$$

If the altimeter antenna axis is directed strictly at nadir, the contribution of each part of water and land to the reflection is described by the analogue of Brown's formula:

$$
\begin{aligned}
& P_{k}(\tau)=\frac{P_{0} \sigma_{k}^{(0)}}{4 \pi h^{4}} \exp \left(-\left((4 / \gamma)+\alpha_{k}\right)\left(\left(c \tau-2 H_{k}\right) / h\right)\right) \times \\
& \times\left(1+\operatorname{erf}\left(\frac{\left(c \tau-2 H_{k}\right)}{\sqrt{2} \sqrt{\left(2 s_{k}\right)^{2}++c^{2} \tau_{i}^{2}}}\right)\right) \Delta \varphi_{k}
\end{aligned}
$$

where $h$ is the mean distance from the satellite to the underlying surface. The parameters with index $k$ : $H_{k}, \alpha_{k}, s_{k}$ correspond to the level, scattering properties and roughness for a given $(k$-th) part of the underlying surface $\left(H_{k}\right.$, is the deviation of the surface level from the mean value, it is positive when the distance from the surface to the satellite is greater than the mean value and the surface level is lower than the mean value) (Troitskaya et al. 2012b). In (2) we take into account the fact that at time $\tau=t-2 \mathrm{~h} / \mathrm{c}$ the main contribution to the reflection from the $k$-th illuminated area is given by an arc $\Delta \varphi_{k}$ centred at the nadir point with coordinates $x_{N}, y_{N}$ and determined by the condition of equality of the distance from the antenna to the $k$-th piece of surface (Troitskaya et al. $2012 b)$. The radius of the arc is equal to $\sqrt{h\left(c \tau-2 H_{k}\right)}$ and depends on the deviation of the surface level of this area from the average value. For coastal slicks the reflected power is:

$$
\begin{aligned}
& P_{s l}(\tau)=\frac{P_{0} \sigma_{s l}^{(0)} d_{s l}}{\sqrt{2 \pi} h^{4} s_{s l}} \exp \left[-\left((4 / \gamma)+\alpha_{s l}\right)\left(c \tau-2 H_{\text {water }}\right) / h\right] \times \\
& \times \int_{c} \exp \left[-\left(c \tau-2 H_{\text {water }}-\frac{\left(x(l)-x_{N}\right)^{2}+\left(y(l)-y_{N}\right)^{2}}{h}\right)^{2} / 2 c^{2} \tau_{i}^{2}\right] d l
\end{aligned}
$$

where $x=x(l), y=y(l)$ is the equation of the coastal line $C$, and $d_{s l}$ is the width of the slick (Troitskaya et al. 2012a).

Using equations (1)-(3) one can calculate the reflected waveforms and their change when the satellite moves along the track. Parameters in equations (2) and (3) are determined by the properties of the reflecting surface. For the water surface: elevation $H$ is water level, $s$ is a significant wave height and $\sigma$ is determined by the wind speed. For the land surface, $H$ is determined by topography, $s$ is surface roughness, and $\sigma$ is determined by the reflecting properties of the land. The model was constructed assuming that the land parameters of land, and the characteristics of surface water (water level, wave height and roughness) are variable and must be determined using the retracking algorithm. 
Based on equations (1)-(3), the reflected waveforms for each T/P and J1/2 satellite track for all the lakes were calculated. For the calculation of waveforms, we chose the model surface parameters from physical considerations: for land: $\sigma^{(0)}=20, \alpha=10, \sigma_{s}^{\text {land }}=3 \mathrm{~m}$; for water: $\sigma^{(0)}=50, \alpha=10, \sigma_{s}^{\text {water }}=0.3 \mathrm{~m}$; and for coastal slicks: $\sigma^{(0)} d_{s l}=0.5, \alpha=1000$. The parameters specific to the radar altimeter were set equal to $\gamma=0.0005, \tau_{i}=0.425 T$ (Troitskaya et al. 2012a) $\left(T=3.125 \cdot 10^{-9} \mathrm{~s}-\right.$ the point target response $3 \mathrm{~dB}$ width).

Analysis of the waveforms and their comparison with the waveforms from the SGDR database of Jason-1 enabled us to formulate the first criterion for selecting telemetry impulses for northwest Russia lakes. In these regions the model waveforms are in good agreement with the measured ones, and the leading edge of the waveforms is determined by the reflection from the water surface. In addition to the first criterion, in accordance with the long-term observations at water level gauges, the deviation of the water level from an average value by more than $2-4 \mathrm{~m}$ should be considered erroneous. For the valid waveforms we used regional retracking algorithms appropriate for northwest Russian lakes, including two steps. In the first step we estimate a tracking point determined by a definite threshold. The second step is refinement of the estimates: the alleged weak leading edge -4 points in the neighbourhood of the threshold (see Fig. 12 in Troitskaya et al. 2012b) - are fitted by the error function (taking into account the analytical results):

$$
A\left(1+\operatorname{erf}\left(\frac{\tau-\tau_{R}}{S}\right)\right)
$$

The parameters in (4) are retrieved by minimization of root-mean-square deviations. The minimization procedure was slightly modified in comparison to Troitskaya et al. (2012b). To improve the algorithm convergence the initial value of the parameter $s$, which characterizes SWH on the water surface, was estimated from the mean slope of the leading edge of the waveform. The signal amplitude $A$ is found by averaging the values of the power over several points, following the leading edge. Then the parameter $\tau_{R}$ characterizing the arrival time of the reflected signal is determined by the one-parameter optimization. The modified optimization algorithm provides a more accurate value for the tracking point $\tau_{R}$.

\section{RESULTS AND DISCUSSION}

The water areas of the northwest Russian lakes are crossed by several ground tracks of the T/P and $\mathrm{J} 1 / 2$ altimetry satellites (Fig. 1). The water area of all the lakes is sufficiently large and the reflection conditions are similar to the oceanic area with the exception of the coastal area and the area near the islands (especially true for lakes Ladoga and Onega (Table 1)). But the groundtracks pass near the shore lines and islands, which may lead to pronounced influence of land reflection on the waveform of the received telemetric pulse and consequent errors in water level determination. It is therefore interesting to calculate the water level on the algorithm of regional retracking to compare results with in situ level gauges data. Our results computation showed that the satellite altimetry data correspond well to the gauged data with a determination coefficient 0.976-0.998.

According to the results (Fig. 3), the temporal variability of Lake Ilmen water level is characterized by a wave with a period of 4-5 years (maximum in 2001, 2004, 2008 and minimum in 1997, 2003, 2008). Between 2000 and 2011, lake level rose at a rate of $1.17 \pm 0.95 \mathrm{~cm} /$ year. The level of Lake Ladoga also showed a wave with period of 4-5 years (maximum in 1995, 1999, 2005, 2010 and minimum in 2003, 2006, 2009). From 1993 to 2011, lake level decreased at a rate of $0.24 \pm 0.10 \mathrm{~cm} /$ year. A similar wave is observed in Lake Piepus level (maximum in 1995, 1999, 2005, 2010 and minimum in 1997, 2003, 2008). During the period from 1993 to 2011, its level was rising at a rate of $1.39 \pm 0.18 \mathrm{~cm} /$ year. In the interannual variability of Lake Onega level we found a wave with a period of 15 years (maximum in 1995 and 2009, and minimum in 2003). From 1993 to 2011, lake level was decreasing at a rate of $0.18 \pm 0.09 \mathrm{~cm} /$ year.

The local adaptive retracking algorithm enables retrieving of water level even in the case of smaller water basins with a very complex reflecting surface. It works well for both T/P and J1/2 


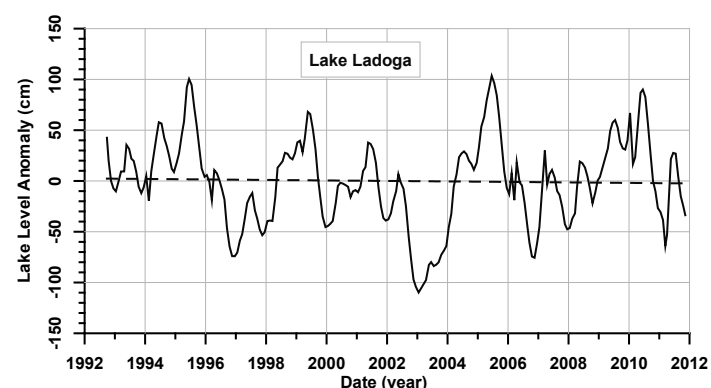

(a)

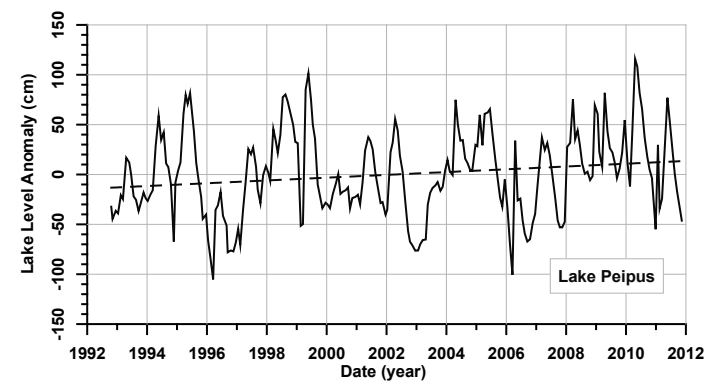

(c)

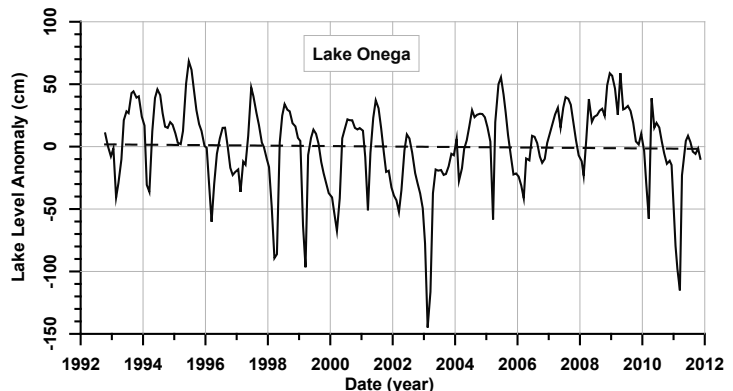

(b)

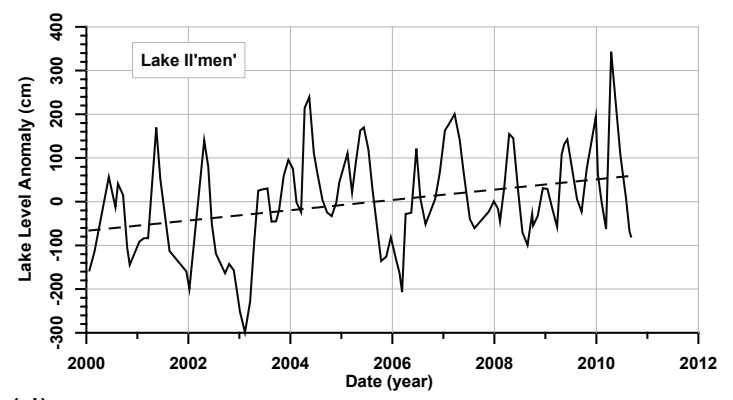

(d)

Fig. 3 Temporal variability water of Lake Ladoga (a), Lake Onega (b), Lake Peipus (c) and Lake Il'men (d), based on altimetric measurements by the T/P and J1/2 satellites.

SGDR data. Application of the algorithm increases significantly the number of valid data and improves dramatically the accuracy of water level retrieval from the altimetry data. The problems of inland water data processing are very similar to those arising in the coastal zones of the ocean and other complex areas due to contamination of the received signal by reflection from the land. Therefore, the adaptive retracking algorithm based on calculations of the waveforms taking into account inhomogeneity of the reflecting surface adjusted to a certain geographic region, allows construction of a step-by-step strategy for improving estimations of water level and other hydrological parameters in such areas.

Acknowledgements This study was supported by a series of grants from the Russian Foundation for Basic Research, no. 13-05-01125, and the Russian Science Foundation, no 14-17-00371.

\section{REFERENCES}

Barrick, D. and Lipa, B. (1985) Analysis and interpretation of altimeter sea echo. Adv. Geophys. 27. 61-100. doi: 10.1016/S0065-2687(08)60403-3

Berry, P.A.M., et al. (2005) Global inland water monitoring from multimission altimetry. Geophys. Res. Lett. 32(16), L16401. doi: 10.1029/2005GL022814.

Birkett, C.M. and Beckley, B. (2010) Investigating the performance of the Jason-2/OSTM radar altimeter over lakes and reservoirs. Marine Geodesy 33(1), 204-238. doi: 10.1080/01490419.2010.488983.

Birkett, C.M., et al. (2002) Surface water dvnamics in the Amazon Basin: Application of satellite radar altimetry. J. Geophys. Res., 107(D12), 8059,. doi: 10.1029/2001JD000609.

Brown, G. (1977) The average impulse response of a rough surface and its applications. IEEE Trans. Antennas Propagat. 25(1), 67-74. doi: 10.1109/TAP.1977.1141536.

Calmant, S. and Seyler, F. (2006) Continental surface waters from satellite altimetry. Geosciences C.R., 338, 1113-1122.

Campos, I.O., et al. (2001) Temporal variations of river basin waters from Topex/Poseidon satellite altimetry. Application to the Amazon basin. Earth and Planetary Sciences 333(10), 633-643. doi: 10.1016/S1251-8050(01)01688-3

Cretaux, J.-F.; et al. (2011) Lakes studies from satellite altimetry. In: Coastal Altimetry (ed. by S. Vignudelli, et al.), 509-534. Springer-Verlag. doi: 10.1007/978-3-642-12796-0_19

Davis, C.H. (1997) A robust threshold retracking algorithm for measuring ice sheet surface elevation change from satellite radar altimeters. IEEE Trans. Geosci. Remote Sens. 35(4), 974-979. doi:10.1109/36.602540

Deng, X. and Featherstone, W. E. (2006) A coastal retracking system for satellite radar altimeter waveforms: Application to ERS-2 around Australia. J. Geophys. Res. 111(C6). C06012. doi: 10.1029/2005JC003039

Guo, J., et al. (2009) Lake level variations monitored with satellite altimetry waveform retracking. IEEE J. Sel. Topics Appl. Earth Observ. Remote Sens. 2(2), 80-86. 
Kouraev, A.V., et al. (2004) Ob' river discharge from TOPEX/Poseidon satellite altimetry (1992-2002). Remote Sens. Environ. 93(1-2), 238-245. doi: 10.1016/j.rse.2004.07.007.

Lebedev, S.A. and Kostianoy, A.G. (2005) Satellite Altimetry of the Caspian Sea (in Russian).

Mercier, F., et al. (2010) Coastal and Hydrology Altimetry Product (PISTACH) Handbook.

Tournadre. J.. et al. (2006) A satellite altimeter model for ocean slick detection. J. Geophys. Res., 111(C4). C04004. doi: $10.1029 / 2005 \mathrm{JC} 003109$

Troitskaya, Y., et al. (2012a) Adaptive retracking of Jason-1 altimetry data for inland waters: the example of the Gorky Reservoir. Int. J. Remote Sens. 33, 7559-7578.

Troitskava. Y.I.. et al. (2012b) Satellite altimetry of inland water bodies. Water Resources 39(2), 184-199. doi: $10.1134 / \mathrm{S} 009780781202008 \mathrm{X}$

Troitskaya, Y., et al. (2013) Adaptive retracking of Jason-1, 2 satellite altimetry data for the Volga River reservoirs. IEEE J. Sel. Topics Appl. Earth Observ. Rem. Sens, PP(99), 1-6. doi: 10.1109/JSTARS.2013.2267092. 